Jurnal Teknik Hidro

Vol. 12 No. 1, Februari 2019

\title{
ANALISIS PERUBAHAN DASAR SALURAN TERBUKA AKIBAT VARIASI DEBIT PADA TINGKAT ALIRAN KRITIS DAN SUPER KRITIS
}

\author{
Rasmawati Rauf ${ }^{(1}$ dan Sufiah Nur $M^{(2}$ \\ ${ }^{1)}$ Universitas Muhammadiyah Makassar, \\ Email : rasmawatirauf94@gmail.com \\ ${ }^{2)}$ Mahasiswa Program Studi Sipil Pengairan Fakultas Teknik \\ Email: sufiahnurm344@gmail.com
}

\begin{abstract}
ABSTRAK
Akibat dari perubahan volume angkutan sungai dapat menyebabkan bentuk dasar sungai berubah-ubah. Angkutan sedimen dasar (bed load) terjadi dipengaruhi oleh kondisi aliran meliputi debit aliran $(Q)$, kemiringan dasar saluran $(S)$, serta variasi komposisi sedimen dasar. Tujuan dari penelitian ini adalah untuk mengetahui pengaruh kecepatan aliran dan perubahan bentuk dasar (bedforms) saluran terbuka pada kondisi kritis dan superkritis dengan debit yang berbeda. Metode peneltian dilakukan dengan model fisik di laboratorium. Untuk mengetahui dan menetapkan jenis aliran yang terjadi dalam proses pengaliran pada saluran digunakan perhitungan bilangan Froude (Fr). Berdasarkan pada pengukuran dan perhitungan meliputi : debit yaitu (Untuk $Q_{1}=0,0057 \mathrm{~m}^{3} / \mathrm{dtk}$, untuk $Q_{2}=0,0086 \mathrm{~m}^{3} / d t k$, dan untuk $\left.Q_{3}=0,0104 \mathrm{~m}^{3} / d t k\right)$. dengan $h(0,084-0,099)$ kecepatan $(0,57 \mathrm{~m} /$ det $-0,96 \mathrm{~m} /$ det $)$. Serta hasil penelitian menunjukkan bahwa Pengaruh kecepatan aliran terhadap perubahan dasar pada kondisi aliran kritis dan superkritis yaitu besarnya kecepatan berbanding lurus dengan angka Froude, semakin tinggi kecepatan semakin besar angka Froudenya. Perubahan bentuk dasar saluran ( bedforms ) terbuka rata - rata berubah kebentuk transition. Kemudian untuk aliran superkritis berubah ke bentuk antidunes karena kecepatan aliran semakin tinggi.
\end{abstract}

Kata kunci : Perubahan Dasar, Debit, Bilangan Froude

\begin{abstract}
As a result of changes in the volume of river transport may cause the form of the river bottom to vary. Bed load transport is influenced by flow conditions including flowrate $(Q)$, basal slope $(S)$, and variation of base sediment composition. The purpose of this research is to know the effect of flow velocity and change the open bed form (bedforms) in critical condition and supercritical with different discharge. The method of research is done by physical model in laboratory. To determine and determine the type of flow that occurs in the drainage process on the channel is used the calculation of the Froude number (Fr). Based on the measurements and calculations include: discharge ie (For Q1 $=0.0057 \mathrm{~m} 3 / \mathrm{s}$, for $Q 2=0.0086 \mathrm{~m} 3 / \mathrm{s}$, and for $Q 3=0.0104 \mathrm{~m} 3 / \mathrm{s})$. With $h(0.084$ $0,099)$ velocity $(0.57 \mathrm{~m} / \mathrm{s}-0.96 \mathrm{~m} / \mathrm{s})$. And the results showed that the influence of flow velocity to the basic changes in critical and supercritical flow conditions ie the amount of speed is directly proportional to the number Froude, the higher the speed the greater the number Froudenya. Changes in the form of open bedforms (averages) open on average changed form transition. Then for the supercritical flow changes to the antidunes form because the flow rate is getting higher.
\end{abstract}

Keywords: Basic Changes, Debits, Froude Numbers 


\section{PENDAHULUAN}

Debit yang mengalir pada suatu penampang terbuka lebih mudah diamati dibanding debit pada penampang tertutup, namun untuk analisanya justru kebalikannya. Debit air adalah kecepatan aliran zat cair persatuan waktu. Debit juga didefenisikan sebagai hasil perkalian antara kecepatan dengan luas penampang. Semakin besar kecepatan dan luas penampang maka akan semakin besar pula debit yang dihasilkan. Kecepatan itu sendiri adalah besarnya jarak yang ditempuh persatuan waktu.

Fenomena bentuk dasar (bedforms) pada sungai sering kita jumpai dalam morfologi sungai. Bentuk dasar ini terjadi disebabkan oleh aliran (flow induced) dan pengaruh kekasaran dasar (roughness).

Akibat dari perubahan volume angkutan sungai dapat menyebabkan bentuk dasar sungai berubah-ubah. Angkutan sedimen dasar (bed load) terjadi dipengaruhi oleh kondisi aliran meliputi debit aliran (Q), kemiringan dasar saluran (S), serta variasi komposisi sedimen dasar.
Tujuan dari penelitian ini untuk mengetahui pengaruh kecepatan aliran dan perubahan bentuk dasar (bedforms) saluran terbuka pada kondisi kritis dan superkritis dengan debit yang berbeda.

\section{TINJAUAN PUSTAKA}

\section{Saluran Terbuka}

Saluran yang mengalirkan air dengan suatu permukaan bebas disebut saluran terbuka. Kajian tentang perilaku aliran dikenal dengan mekanika fluida (fluid mechanis). Hal ini menyangkut sifat-sifat fluida dan pengaruhnya terhadap pola aliran dan gaya yang akan timbul di antara fluida dan pembatas (dinding). Telah diketahui secara umum bahwa akibat adanya perilaku terhadap aliran untuk memenuhi kebutuhan manusia, menyebabkan terjadinya perubahan alur aliran dalam arah horizontal maupun vertikal.

Saluran buatan adalah saluran yang dibuat dan direncanakan sesuai dengan konteks pemanfaatnya seperti, saluran irigasi, saluran drainase, saluran pembawa pada pembangkit listrik tenaga air dan saluran untuk industri dan sebagainya termasuk model saluran yang dibuat di 
laboratorium untuk keperluan penelitian.

\section{Bentuk Dasar (bedforms)}

Bentuk dasar saluran adalah konfigurasi yang ditemukan pada dasar sungai sebagai hasil dari kumpulan ukuran partikel yang tidak teratur.

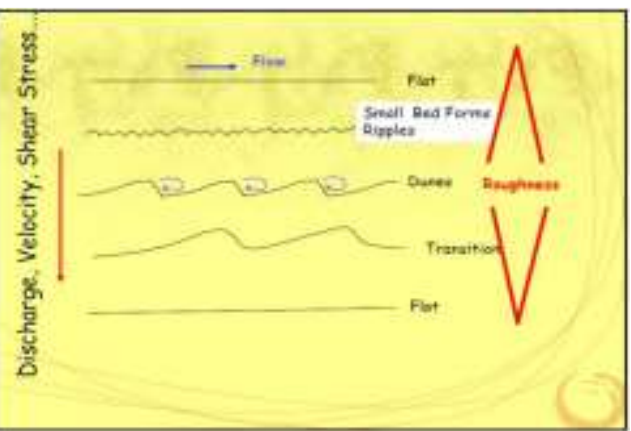

Gambar 1. Bentuk-bentuk dasar sungai (sumber : Shimizu, 2009)

Transpor sedimen di dasar sungai akan membentuk konfigurasi dasar sungai. Bentuk - bentuk konfigurasi dasar sungai memiliki karakteristik dan hukum yang teratur dan dapat diklasifikasikan ke dalam mikrostruktur dan makrostruktur.

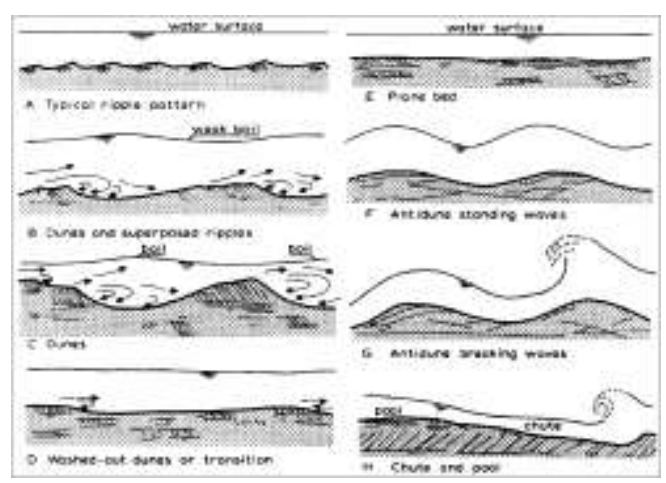

Gambar 2. Konfigurasi Dasar Sungai

\section{Karakteristik Aliran}

Karakteristik aliran adalah gambaran spesifik mengenai aliran yang dicirikan oleh parameter yang berkaitan dengan keadaan topografi, tanah, geologi, vegetasi, penggunaan lahan, hidrologi, dan manusia.

1) Sifat-sifat aliran berdasarkan pengaruh gaya kelembaman dengan gaya kekentalan dikenal dengan angka Reynold (Re) yaitu: $\mathrm{R}=\frac{u L}{v}$

2) Sifat-sifat aliran berdasarkan Perbandingan gaya kelembaman dengan gaya Gravitasi.

$$
F r=\frac{\tilde{\mathrm{v}}}{\sqrt{g \cdot h}}
$$

\section{Angkutan Sedimen}

\section{Pengertian Sedimen}

Sedimen adalah hasil proses erosi, baik berupa erosi permukaan, erosi parit, atau jenis erosi tanah lainnya. Sedimen umumnya mengendap di bagian bawah kaki bukit, di daerah genangan banjir, di saluran air, sungai, dan waduk. Hasil sedimen (sediment yield) adalah besarnya sedimen yang berasal dari erosi yang terjadi di daerah tangkapan air yang diukur pada periode waktu dan tempat tertentu. Proses erosi terdiri atas tiga 
bagian yaitu : pengelupasan

(detachment),

pengangkutan

(transportasion), dan pengendapan (sedimentation) (Asdak, 2014).

Angkutan Sedimen (Transport Sedimen)

Menurut Mardjikoen (1987), angkutan sedimen merupakan perpindahan tempat bahan sedimen granular (non kohesif) oleh air yang sedang mengalir searah aliran.

\section{Butiran Sedimen}

Gradasi atau susunan butir adalah distribusi dari ukuran agregat. Distribusi ini bervariasi dapat di bedakan menjadi tiga yaitu gradasi sela (gap grade), gradasi menerus (continous grade) dan gradasi seragam (uniform grade).

Volume Sedimen Dengan Rumus Kalinskie

$$
\begin{aligned}
& \frac{q s}{U^{*} d_{65}}=\left(\frac{\tau_{C}}{\tau_{o}}\right) \\
& q_{B}=q_{s} \cdot \gamma_{s} . \\
& Q_{B}=B \cdot q_{B} \ldots
\end{aligned}
$$

\section{METODE PENELITIAN}

\section{Lokasi dan Waktu Penelitian}

Penelitian dilaksanakan di labotatorium Fakulatas Teknik Sipil Universitas Muhammadiyah Makassar dengan rencana waktu penelitian selama 6 bulan yaitu dimulai bulan September-Oktober mencari referensi, November persiapan, Desember-Januari masuk Laboratorium untuk pelaksanaan penelitian dan di bulan Februari pengolahan data.

\section{Model Saluran}

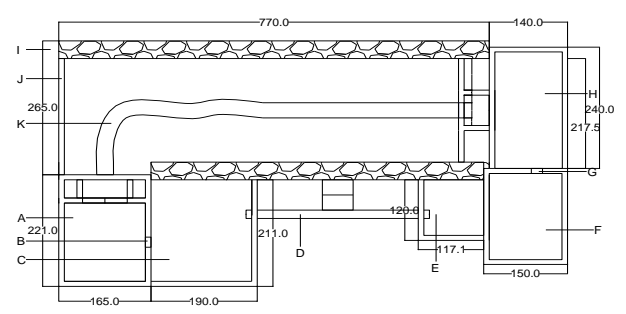

Gambar 3. Denah Model Penelitian

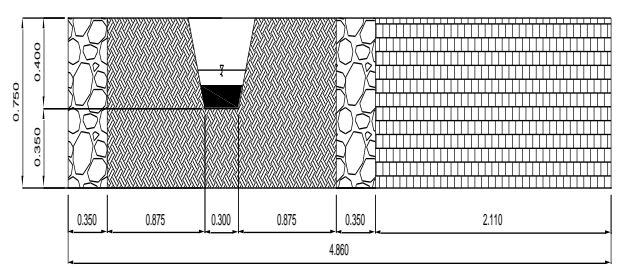

Gambar 4.Potongan Melintang Penampang Saluran Terbuka

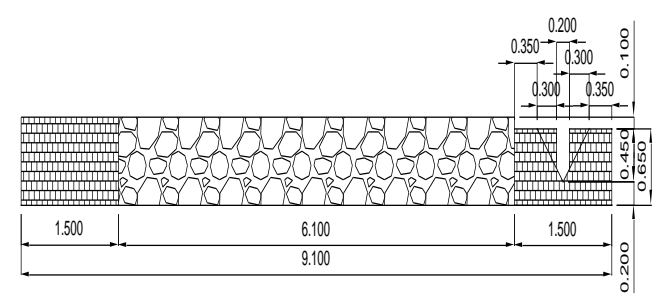

Gambar 5. Potongan Memanjang Penampang Saluran Terbuka

\section{Prosedur Penelitian}

1) Meratakan pasir dalam saluran dengan menggunakan pasir non kohesif (granuler) diatas saluran dengan tebal $10 \mathrm{~cm}$. 


\section{Jurnal Teknik Hidro}

\section{Vol. 12 No. 1, Februari 2019}

2) Kalibrasi semua peralatan yang akan digunakan khususnya alat ukur kecepatan.

3) Melakukan pengaliran awal untuk mengetahui layak atau tidaknya saluran yang akan digunakan dalam pengaliran (Running kosong).

4) Mengalirkan air sesuai debit (Q) yang ditentukan dengan membuka pintu saluran setinggi $1 \mathrm{~cm}$

5) Pengambilan data kecepatan aliran (V) dan Tinggi muka air (h) pada saat yang telah ditentukan pada waktu $\left(\mathrm{t}_{1}: 8\right.$ menit, $\mathrm{t}_{2}: 14$ menit, dan $t_{3}: 20$ menit)

6) Mematikan pompa pada saat waktu 8 menit (waktu yang ditentukan) untuk pengambilan data perubahan dasar saluran (pencatatan data)

7) Setelah selesai pengambilan data percobaan pertama, Ulangi langkah kedua, ketiga, keenam,

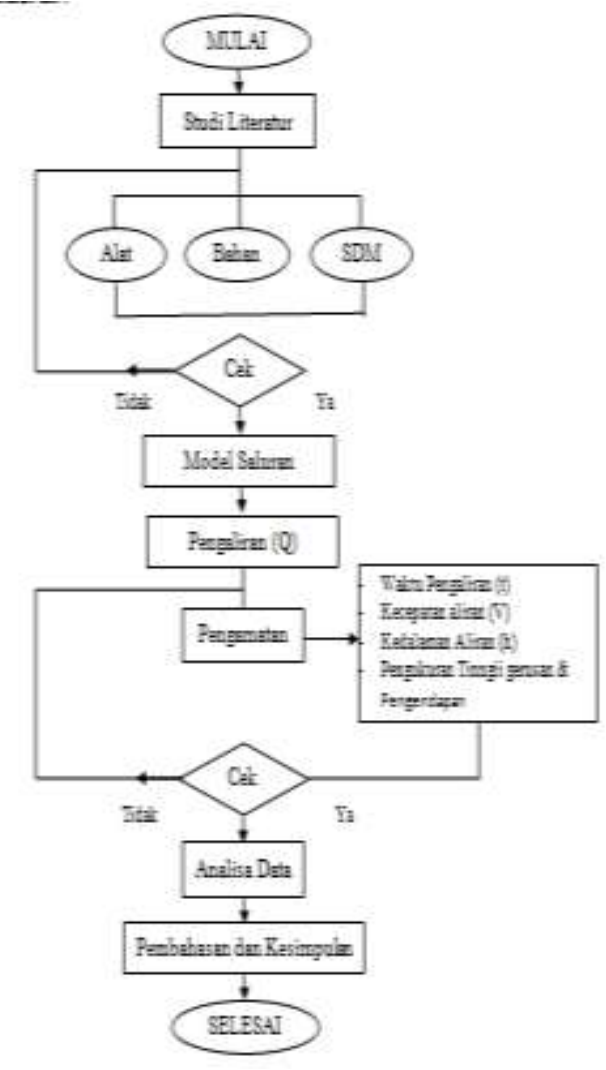

Gambar 6. Flow chart penelitian

\section{HASIL DAN PEMBAHASAN}

Pengaliran pada Saluran Terbuka

Hasil perhitungan bilangan Froude setiap variasi debit dan waktu yang 
digunakan dalam penelitian, dapat dilihat pada tabel berikut :

Tabel 1. Perhitungan Bilangan Froude

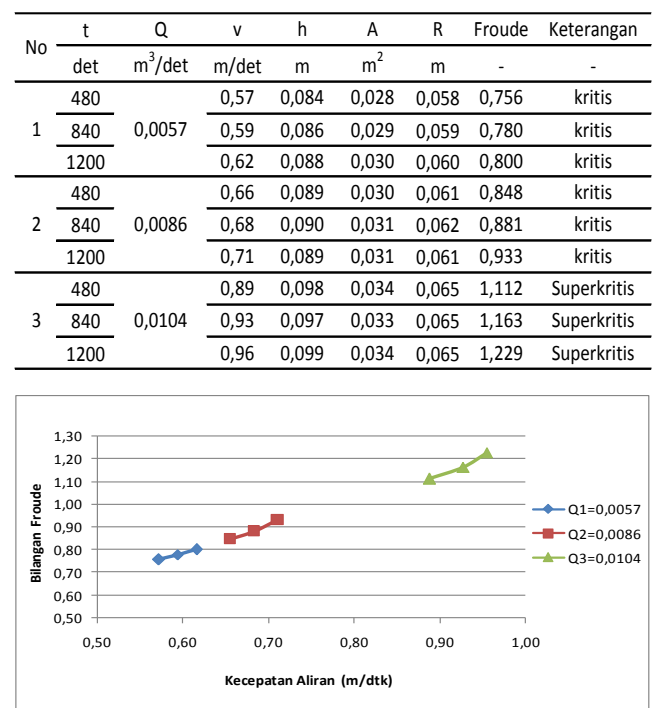

Gambar 7. Grafik hubungan angka Froude dengan kecepatan

Pada grafik diatas menunjukkan Besarnya kecepatan berbanding lurus dengan angka Froude, semakin tinggi kecepatan semakin besar angka Froudenya

Tabel 2. Perhitungan Bilangan Reynold

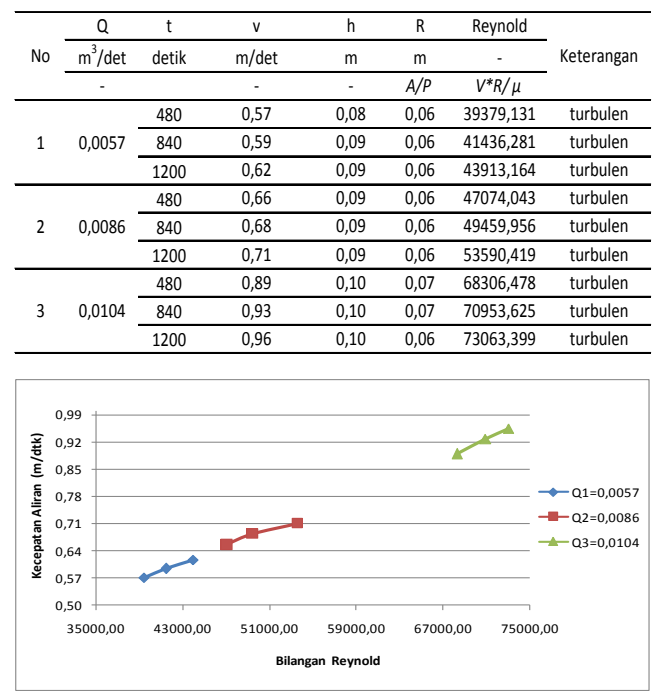

Gambar 8. Hubungan antara kecepatan (m/det) dan Bilangan Reynold

Dari hasil analisa untuk bilangan Reynold dapat diketahui bahwa kecepatan aliran berbanding lurus dengan bilangan Reynold, semakin cepat kecepatan alirannya maka semakin besar pula bilangan Reynoldnya

Pengamatan Bentuk Dasar dengan melihat Kedalaman Gerusan dan Pengendapan terhadap Debit

Tabel 3. Tinggi Gerusan dan Pengendapan dalam satuan $\mathrm{cm}$ pada debit $\mathrm{Q}_{1}=0,0057 \mathrm{~m}^{3} / \mathrm{dtk}$ untuk waktu 480 detik. 
Jurnal Teknik Hidro

Vol. 12 No. 1, Februari 2019

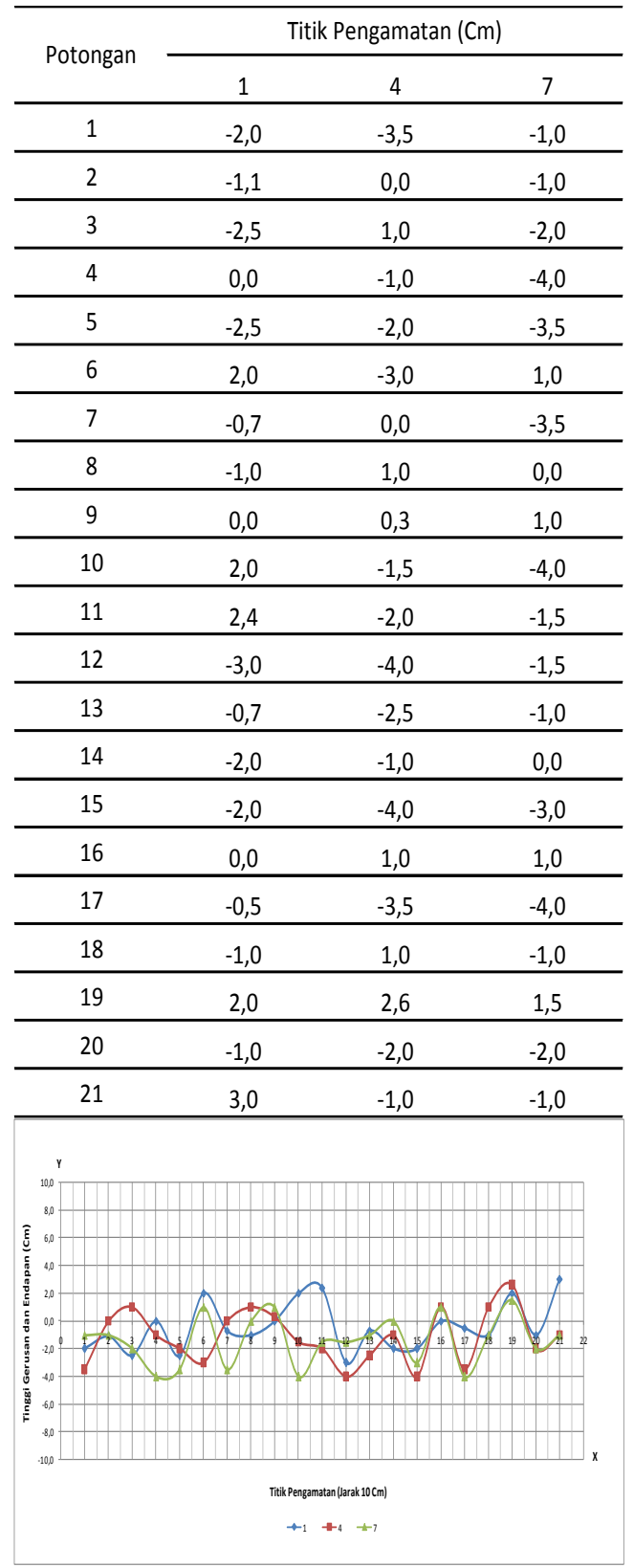

Gambar 9. Grafik tinggi gerusan dan pengendapan pada tingkat aliran kritis

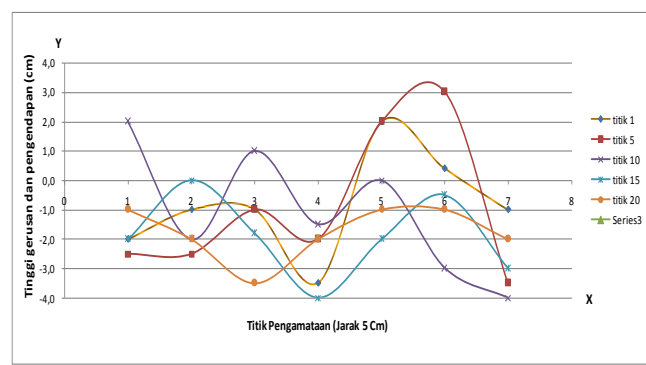

Gambar 10. Grafik tinggi gerusan dan pengendapan pada tingkat aliran kritis

Kedalaman gerusan dan tinggi pengendapan untuk $\mathrm{Q}_{1}=0,0057$ $\mathrm{m}^{3} /$ dtk pada waktu 480 detik yaitu pada titik 1 kedalaman gerusannya mencapai $3,0 \mathrm{~cm}$ atau $0,03 \mathrm{~m}$ dan tinggi pengendapannya mencapai 2,4 $\mathrm{cm}$ atau 0,024 m. Untuk titik 4 Kedalaman gerusannya mencapai 3,5 $\mathrm{cm}$ atau $0,035 \mathrm{~m}$ dan tinggi pengendapannya mencapai $2,6 \mathrm{~cm}$ atau $0,026 \mathrm{~m}$. Kemudian pada titik 7 Kedalaman gerusannya mencapai 4,0 $\mathrm{cm}$ atau 0,04 $\mathrm{m}$ dan tinggi pengendapannya mencapai $1,0 \mathrm{~cm}$ atau $0,01 \mathrm{~m}$.

\section{Pengaruh Kecepatan terhadap}

\section{Perubahan Bentuk Dasar Saluran}

Penelitian ini dilakukan dengan menggunakan 2 variasi waktu yakni 14 menit dan 20 menit dan 3 variasi debit yakni $0,0057 \mathrm{~m}^{3} / \mathrm{dtk}, 0,0086$ $\mathrm{m}^{3} / \mathrm{dtk}, \quad 0,0104 \quad \mathrm{~m}^{3} / \mathrm{dtk}$. Cara pengamatan dilakukan dengan mencatat kecepatan aliran menggunakan current meter dan tinggi muka air menggunakan mistar ukur pada setiap variasi waktu, sesuai dengan bukaan pintu di hulu saluran. 
Untuk mengetahui bentuk konfigurasi dasar saluran dalam penelitian ini peneliti menggunakan dua pendekatan yakni dengan menggunakan grafik Albertson. Pertama membandingkan antar angka Froued $\frac{\tau_{0}}{\left(\rho_{s}-\rho_{w}\right) g d_{50}}$ dengan dan membandingkan antara $R e=\frac{U_{*} \cdot d}{v}$ dengan $\frac{U_{*}}{w}$.

Tabel 4. Rekapitulasi hasil pengamatan perubahan dasar saluran

\begin{tabular}{|c|c|c|c|c|c|c|c|c|}
\hline $\begin{array}{l}\text { Debit(Q) } \\
\text { (m33/dtk) }\end{array}$ & $\begin{array}{c}\operatorname{Waktu}(\mathrm{I}) \\
(\mathrm{dtk})\end{array}$ & $\begin{array}{c}\text { Froude } \\
(\mathrm{Fr})\end{array}$ & $\mathrm{U}_{*}$ & $U_{-} / W$ & $\operatorname{Re}$ & $C d$ & W & Konfigururasi Dasar \\
\hline \multirow{3}{*}{0,0057} & 840 & 0,756 & 0,041 & 0,117 & 113,982 & 0,211 & 0,492 & transition \\
\hline & 1200 & 0,780 & 0,041 & 0,116 & 115,108 & 0,208 & 0,494 & transition \\
\hline & 840 & 0,800 & 0,041 & 0,116 & 116,594 & 0,206 & 0,497 & transition \\
\hline \multirow{3}{*}{0,0086} & 1200 & 0,448 & 0,042 & 0,111 & 117,329 & 0,205 & 0,499 & transition \\
\hline & 840 & 0,881 & 0,042 & 0,109 & 118,06 & 0,203 & 0,501 & transition \\
\hline & 1200 & 0,933 & 0,042 & 0,103 & 117,095 & 0,204 & 0,500 & transition \\
\hline \multirow{3}{*}{0,0104} & 480 & 1,112 & 0,044 & 0,095 & 123,056 & 0,195 & 0,511 & antidunes \\
\hline & 840 & 1,163 & 0,044 & 0,090 & 122,706 & 0,196 & 0,510 & antidunes \\
\hline & 1200 & 1,229 & 0,044 & 0,089 & 123,753 & 0,194 & 0,512 & antidunes \\
\hline
\end{tabular}

\section{PENUTUP}

\section{Kesimpulan}

Berdasarkan hasil penelitian yang telah dilakukan maka disimpulkan:

1) Pengaruh kecepatan aliran terhadap perubahan dasar yaitu besarnya kecepatan berbanding lurus dengan angka Froude, semakin tinggi kecepatan semakin besar angka Froudenya. Untuk $\mathrm{Q}_{1}=0,0057 \mathrm{~m}^{3} / \mathrm{dtk}$, untuk $\mathrm{Q}_{2}=0,0086 \mathrm{~m}^{3} / \mathrm{dtk}$, dan untuk $\mathrm{Q}_{3}$ $=0,0104 \mathrm{~m}^{3} / \mathrm{dtk}$.
2) Bentuk dasar saluran (bedforms) saluran trbuka pada aliran kritis dengan variasi debit yang berbeda yaitu bentuk dasar rata rata berubah kebentuk transition. Kemudian untuk aliran superkritis berubah ke bentuk antidunes karena kecepatan aliran semakin tinggi.

\section{Saran}

Kami sadar penelitian ini jauh dari kesempurnaan, oleh karena itu kami menyarankan mengkaji lebih lanjut dengan menggunakan variasi kemiringan dan variasi butiran karena kemiringan dan variasi butiran berpengaruh pada bentuk dari konfigurasi dasar saluran.

\section{DAFTAR PUSTAKA}

Asdak, C. 2014. Hidrologi dan Pengolahan Daerah Aliran Sungai. Gajah Mada University Press, Yogyakarta.

Chow V.T.,1992.Hidrolika Saluran Terbuka (Open Channel Hydraulics) Terjemahan, Erlangga : Jakarta.

Hamzah M, Umar. 2013, Studi Pengaruh Lebar Sungai Terhadap Karakteristik Aliran Sedimen di Dasar, Journal Teknik Sipil Universitas Hasanuddin, Makassar (http ://google,diakses 04 September 2014). 
Ikhsan, Cahyono. 2007, Pengaruh Variasi Debit Air Terhadap Laju Bed Load pad Saluran Terbuka dengan Palo Aliran Steady Flow, Media Teknik Sipil. (http://google,diakses 04 September 2014).

Kodoatie Robert., J. Edisi Revisi 2009. Hidrolika terapan, Andi Offset: Yogyakarta.

Karim, T Nenny. Bahan Kuliah Angkutan Sedimen, Teknik Sipil Unismuh Makassar, 2010.

Maedjikoen, Pragnyono, Transportasi Sedimen, UGM.

Mokonio, dkk, 2013 ,Analisis Sedimentasi Di Muara Sungai Saluwangko Di DesaTounelet Kecamatan Kakas Kabupaten Minasahasa, Jurnal Sipil Statik Vol.1 No.6. Universitas Sam Ratulangi.(http://google,diakses 09 November 2014).

Pallu, Saleh, 2011, Diklat sedimen transport, Teknik Sipil universitas Hasanuddin.

Subary 2005, Volume Angkutan Sedimen dipengaruhi oleh Kecepatan Aliran, Media Komunikasi Teknik Sipil Universitas Sriwijaya Palembang, Palembang (http ://google,diakses 15 Januari 2014).

Sukri, 2005 tesis studi konfigurasi dasr saluran di tikungan 900 program pasca sarjana universitas dipenogor0.

Triatmodjo, Bambang. 2008, Hidraulika II, Beta Offset, Yogyakarta 